\title{
Mechanical and Barrier Properties Enhancement in Film Extruded Bio-Polyamides With Modified Nanoclay
}

\author{
Daniele Battegazzore $\mathbb{D}^{1},{ }^{1 *}$ Angela Sattin, ${ }^{1}$ Maria Lluisa Maspoch, ${ }^{2}$ Alberto Frache ${ }^{1}$ \\ ${ }^{1}$ Dipartimento di Scienza Applicata e Tecnologia, Politecnico di Torino, Alessandria site, Viale Teresa Michel 5, \\ 15121 Alessandria, Italy \\ ${ }^{2}$ Centre Català del Plàstic (CCP)-Unversitat Politècnica de Catalunya Barcelona Tech (EEBE-UPC). C/Colom, \\ 114, Terrassa 08222, Spain
}

\begin{abstract}
The plastics industry is increasingly oriented towards the use of bio-based polymers replacing the fossil-based ones. Bio-based polyamides (PAs) in the film packaging application are not still used and need enhancement to overcome some drawbacks. In this scenario, fully (PA10.10) and partially (PA6.10) bio-based PAs were extruded in a laboratory sheet-casting machine. The materials used to obtain films were previously melt blended with modified clay in a twin-screw extruder. The resulting films were morphologically investigated through the scanning electron microscope. The magnifications show agglomerated particles and the packed layers are preferentially aligned in the extrusion machine direction. $X$-rays confirm that $5 \mathrm{wt} \%$ of clay content is difficult to exfoliate in such matrices. The crystallinity was studied by using X-ray diffraction (XRD) and differential scanning calorimetry. The XRD results show coexisting $\alpha$ and $\gamma$ phases in the PA6.10 while the presence of only $\gamma$ in the PA10.10. The presence of clay platelets constrains the crystallites formation, especially in the more polar PA6.10, resulting in changes in the type and the amount of crystals. The mechanical analysis data showed that $5 \mathrm{wt} \%$ of clay induced significant improvement in Young's modulus (+68 and $+14 \%$ ), a slight increase in the tensile yield stress $(+21$ and $+5 \%)$ and only a surprisingly small decrease in the deformation at break (-15 and $-24 \%)$ for PA10.10 and PA6.10, respectively. Furthermore, the addition of clay gave the best oxygen barrier properties reaching a value of $1.8 \pm 0.2 \mathrm{~cm}^{3} \times \mathrm{mm} / \mathrm{m}^{2} \times$ day $\times$ atm comparable to a commercial PA6 film used in the packaging field. POLYM. COMPOS., 2018. @ 2018 Society of Plastics Engineers
\end{abstract}

\section{INTRODUCTION}

The plastics industry is increasingly oriented towards the use of polymers from natural origin (bio-based)

Correspondence to: D. Battegazzore; e-mail: daniele.battegazzore@ polito.it

Contract grant sponsor: Spanish Ministry of Economy and Competitiveness; contract grant number: MAT2016- 80045-R.

DOI $10.1002 /$ pc. 25056

Published online in Wiley Online Library (wileyonlinelibrary.com).

(C) 2018 Society of Plastics Engineers replacing plastics derived from petrol chemistry (fossilbased). This new generation of materials will reduce the polymers industry dependency on petroleum, creating more sustainable alternatives $[1,2]$. The bio-based polymers can be classified under two categories: the biodegradable polymers such as PLA (polylactic acid), polyhydroxyalkanoates, starch, cellulose, and the non-biodegradable polymers such as bio-polyethylene, bio-polyethylene terephthalate and bio-PAs (polyamides) [3].

The forecast data published by the European Bioplastics [3] clearly report that such bio-based polymers are continuously growing and the greatest increase in their production will occur for the bio-based but not biodegradable section. Recently, some aliphatic PAs from bio sources were revalued by industries for packaging and for long-term applications, but they are still under investigation [4-6].

Bio-PAs are synthesized from monomers which belong to amino acid, cyclic amide (lactam), dicarboxylic acid, and diamine families. Fatty acids present in vegetable oils can be converted into suitable bifunctional monomers for the production of PAs by a simple polycondensation process. Among most known biomonomers, sebacic acid is produced by conversion of ricinoleic acid derived from castor oil [7]. Generally, the common petroleum based PAs are extensively used in the high temperature durable application as well as in food packaging, while bio-based ones do not fulfill the industrial application requirements [7]. Indeed, PA6 is extensively used in food packaging due to its high stiffness, toughness, tensile strength, flex crack, and puncture resistance as well as low oxygen transmission rate (OTR) [8] while bio-based polyamides (PA10.10, PA11, PA12, PA6.10, etc.) are not still used and there are only few studies about the enhancement of the drawbacks [4,5,9-13]. Most of these food packaging are made by a sheet cast machine that also uniaxially or biaxially stretches the extruded film [14]. This device is able to produce a material that is ready to be used for the packaging as a single layer or, more frequently, in a multilayer system [15]. No researches have been published on the use of this new 
class of bio-PAs and this equipment. To achieve quickly a possible industrial exploitation this lack in the literature has to be filled and this paper reports the conditions to produce films from some bio-based PAs. Thus, the first goal of this research was to produce films with PA10.10 (fully biobased) and PA6.10 ( $\approx 60 \%$ bio-based $)$ with a laboratory machine and the second was to evaluate their mechanical and barrier properties.

These two PAs have specifically been chosen in order to find the right compromise between the need to use biobased polymers and the need to maintain a good barrier and mechanical properties. Indeed, such properties change according to the type of PA due to the polarity related to the ratio of the amide group in the chains. Moreover, the stretching conditions affect the structural properties of the films related to the molecular orientation, ability to crystallize and type of crystalline structure, OTR, puncture resistance and clarity $[15,16]$.

PAs generally display different crystalline forms (i.e., $\alpha$ and $\gamma$ ) depending on the processing conditions and thermomechanical history that could be affected by the presence of fillers [17]. In general, fast cooling or quenching and low crystallization temperature promote $\gamma$-form crystals, while higher crystallization temperatures or slow cooling lead to the $\alpha$-form [18]. As a consequence, the films obtained by hot-pressing generally exhibit $\alpha$-form crystals, whereas the crystalline structure of samples obtained from film blowing or casting is more complex and generally results in the coexistence of both $\alpha$ - and $\gamma$-phases [17].

It is also reported in the literature that PAs films cast on cold rolls exhibit the so-called mesomorphic phase or mesophase, otherwise they show $\beta$-form which is hardly distinguishable from the $\gamma$-form by means of X-ray scattering [19]. This metastable mesophase also undergoes reorganization into the $\alpha$-crystal form during the heating scan $[20,21]$.

The $\gamma$ form of PA6 is thermodynamically unstable and is transformed into the $\alpha$ form in plastic drawing [22] or thermal annealing [23]. The $\alpha$ form is highly stable and is typically stiffer than the $\gamma$ form that has a higher modulus and yield stress, and lower strain at break [24]. The PA6 films in the mesomorphic $\gamma$ crystalline form are more ductile than the films in the predominant stable $\alpha$ form $[8,25]$.

A detailed study of the crystallinity has been reported by using XRD and Differential scanning calorimetry (DSC) analyses. Moreover, the stretching orientation was evaluated by comparing the mechanical results in the extrusion direction (MD) and in the transverse direction (TD).

The same bio-PAs have been blended with a modified clay (Cloisite 30B) since clays have been proven to improve the mechanical and barrier performance of fossil based PAs [18,26,27]. Furthermore, during the cast film extrusion process, these nanoplatelets could be oriented in the flow direction and subsequently further enhance their properties $[8,26]$.

Mechanical properties of nanocomposites (5 wt $\%$ ) have been investigated in PA10.10 but not processed with film extrusion. The results revealed that tensile modulus and tensile strength increased 44 and $22 \%$, respectively compared with the neat matrix [12]. In another study Bureau et al. [17] reported that the improvements in rigidity and strength were observed when montmorillonite was added to PA6. These improvements were related to the reinforcing of the filler and not to a modification of the crystalline structure of the matrix.

The presence of the clay is also responsible for the glass-transition temperature $\left(T_{\mathrm{g}}\right)$ increase due to the strong interaction between the clay and the matrix which constrains the movement of the PA chain segments [12].

As far as barrier properties are concerned, Picard et al. [18] studied PA6-montmorillonites membranes obtained from blown film extrusion in a range of clay content from 0 to $18 \mathrm{wt} \%$. OTR of $19.28 \mathrm{~cm}^{3} \times \mathrm{m}^{-2} \times$ day $^{-1}$ and $\mathrm{H}_{2} \mathrm{O}$ permeability coefficient of $4.06 \times 10^{-12} \mathrm{~g} \mathrm{~cm}$ $\mathrm{cm}^{-2} \mathrm{~s}^{-1}$ were reported for neat PA. In this study, these permeability values are more or less halved with the $10 \mathrm{wt}$ $\%$ of clay. In another research Swain and Isayev [28] found that compression molded PA6 film has an oxygen permeability (OP) of $23.05 \mathrm{~cm}^{3} \times \mathrm{mm} / \mathrm{m}^{2} \times$ day $\times$ atm. This value decreases by increasing clay concentration, reaching $5.16 \mathrm{~cm}^{3} \times \mathrm{mm} / \mathrm{m}^{2} \times$ day $\times$ atm with $5 \mathrm{wt} \%$ of Cloisite 30B. Fasihi and Abolghasemi [29] studied the same matrix type and obtained an OP of $1.41 \mathrm{~cm}^{3} \mathrm{~mm} /\left(\mathrm{m}^{2}\right.$ day bar) a value more similar to what generally reported in PA6 [30]. Also in this case, the OP was reduced to $0.33 \mathrm{~cm}^{3} \mathrm{~mm} /\left(\mathrm{m}^{2}\right.$ day bar) (76\%) with the addition of $5 \mathrm{wt} \%$ of clay.

All these works show the ability of clay to decrease both OP and water vapor permeability (WP) in the PA6 but no studies have been carried out on film extruded bio-PAs. Hence, there is a need to have an in-depth understanding of these composites properties related to the processing conditions in a laboratory scale plant. These important data could be the base point for further improvement focused on large-scale packaging applications. As a reference, results with PA6 have been reported to compare the bio-PAs with a commonly used PA for packaging.

\section{MATERIALS AND METHODS}

\section{Materials}

Polyamides. Two kinds of polyamides, PA10.10 and PA6.10, were supplied by Radici Chimica SpA. The PAs have only the "10" structural unit derived from renewable resources.

The raw castor oil is hydrolyzed to give ricinoleic acid, which is then converted to sebacic acid in a reaction with sodium hydroxide at high temperature. In the first step of PA6.10 production, the salt preparation, the sebacic acid is dissolved in water, followed by the addition of hexamethylene diamine. In the second step, the polymerization one, the salt is transferred in a stirred autoclave. Then the polymer is extruded through a die, quenched in cold water, and 


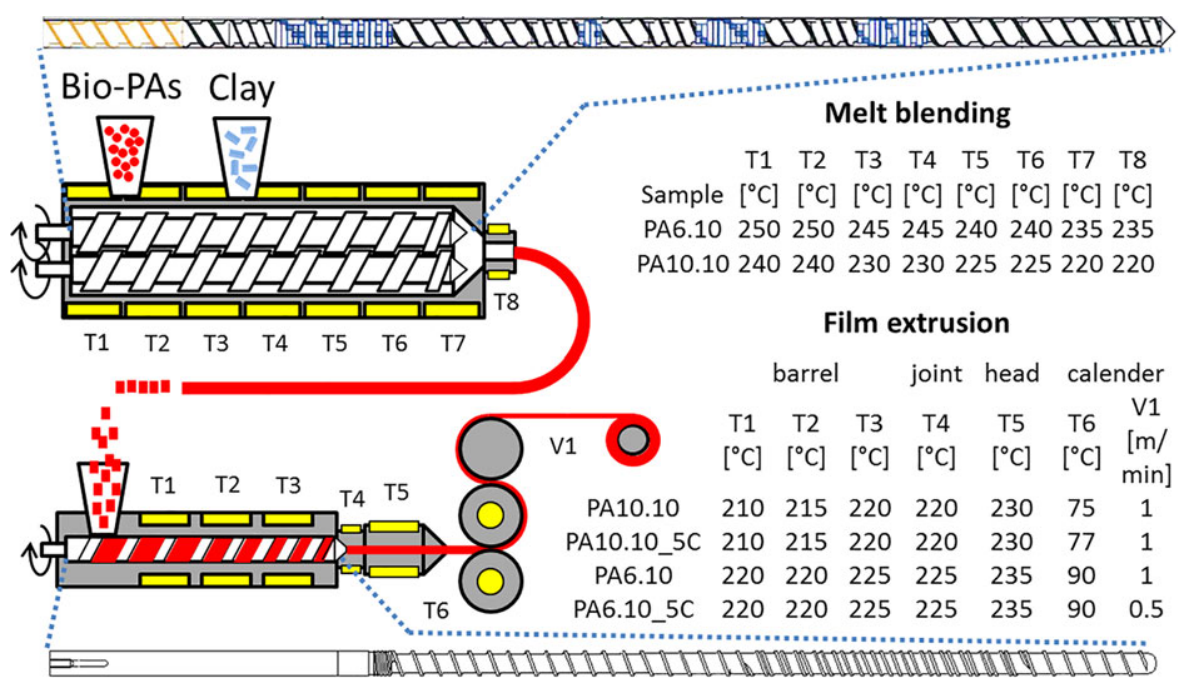

FIG. 1. Twin screw profile and set temperatures for melt blending; process scheme, parameters and screw profile for the film extrusion. [Color figure can be viewed at wileyonlinelibrary.com]

cut into small pellets. The preparation of PA10.10 follows the same procedure already described for PA6.10. The starting monomers are 1,10 decanediamine and sebacic acid, both derived from castor oil. The detailed process to obtain the polymers has already been presented in a previous work [10]. The renewable carbon content of the resulting materials was determined by radiocarbon analysis as 98 and 60\% for PA10.10 and PA6.10, respectively.

PAs densities were between 1.05 and $1.07 \mathrm{~g} / \mathrm{cm}^{3}$ which were used for the volume fraction calculation.

Clay. A natural montmorillonite modified with methyl hydrogenated tallow bis-2-hydroxyethyl quaternary ammonium, (Cloisite ${ }^{\circledR}$ 30B - C30B) was purchased from Southern Clay Products Inc. A density of $1.98 \mathrm{~g} / \mathrm{cm}^{3}$, an organic content of $30 \%$ and a cation exchange capacity of $90 \mathrm{meq} / 100 \mathrm{~g}$ clay were reported by the supplier datasheet.

\section{Composites Preparation}

All PAs were dried at $80^{\circ} \mathrm{C}$ dew point $-40^{\circ} \mathrm{C}$ for $8 \mathrm{~h}$ in an industrial dryer (Piovan HR50) before extrusion, reaching $<200 \mathrm{ppm}$ of water content assessed by Karl-Fisher titration much less than the $1000 \mathrm{ppm}$ suggested by the producer. Analogously, C30B was dried before the extrusion in a vacuum convection oven at $130^{\circ} \mathrm{C}$ for $10 \mathrm{~h}$, as well.

PA-composites were melt blended using a co-rotating twin screw extruder LEISTRITZ ZSE 18/40 D (diameters). The screw speed was fixed at $500 \mathrm{rpm}$. The heating temperature was set in the eight thermostated barrel blocks as reported in Fig. 1. Two gravimetric feeders were used: namely, the main hopper for the polymer was placed at the beginning of the screw and the second one (side feeder) for the filler in the middle of the barrel. Close to the screw end, a degassing hole in the barrel connected to a vacuum pump was present. The total extrusion flow rate was fixed at $3 \mathrm{~kg} / \mathrm{h}$. The used screw profile is reported in Fig. 1 and was optimized in a previous work [10]. Hereafter, the samples will be coded based on the matrix type and the nominal compositions of the filler. Pellets obtained by extrusion were dried at $80^{\circ} \mathrm{C}$ for $8 \mathrm{~h}$ with Piovan HR50 industrial dryer before the film extrusion.

\section{Film Extrusion}

A single screw extruder (Eurotech Extrusion Machinery S.r.1.) with a special screw design $(\mathrm{L}=80 \mathrm{~cm} \mathrm{D}=25 \mathrm{~mm})$ reported in Fig. 1 and a velocity of $20 \mathrm{rpm}$ was used. Temperatures of barrel (T1-T3), joint (T4), and head (T5), calender velocity (V1) were deeply investigated and optimized to obtain a coherent extrusion melt and a homogeneous final film. The values adopted are reported in Fig. 1. The barrel temperature profiles were set to start about $10^{\circ} \mathrm{C}$ above the melting temperatures $\left(T_{\mathrm{m}}\right)$ in the feeding zone (T1) and increasing till $30-40^{\circ} \mathrm{C}$ above $T_{\mathrm{m}}$ in the head zone (T5). The molten polymers were stretched in the machine direction by a calender and finally the resulting film was rolled on a reel. A complete scheme of the process was reported in Fig. 1. The obtained films have a thickness in the range of $120-160 \mu \mathrm{m}$.

\section{Characterization Techniques}

The real percentage of nanoclay in all samples was determined by measuring the residue content in the final film samples after treatment in a hot furnace at $800^{\circ} \mathrm{C}$ in air.

The morphology of bio-composites was studied using a LEO-1450VP scanning electron microscope (SEM) (beam voltage: $5 \mathrm{kV}$; working distance: $10 \mathrm{~mm}$ ); a X-ray probe (INCA Energy Oxford, $\mathrm{Cu}-\mathrm{K} \alpha \mathrm{X}$-ray source, $k=1.540562$ $\AA$ A) was used to perform elemental analysis. The samples were obtained by cryomicrotome Reichert-jung Ultracut 
with sample temperature set to $-150^{\circ} \mathrm{C}$ and the blade temperature to $-50^{\circ} \mathrm{C}$. These pieces were pinned up to conductive adhesive tapes and gold-metalized.

X-ray diffraction (XRD) analyses were performed with PANalytical X'Pert Pro, powered by a Philips PW3040/60 $X$-ray generator and fitted with a PIXcell 1d detector. Diffraction data were acquired by exposing film extruded samples to $\mathrm{Cu}-\mathrm{K} \alpha \mathrm{X}$-ray radiation, which has a characteristic wavelength $(\lambda)$ of $1.5418 \AA$. X-rays were generated from a $\mathrm{Cu}$ anode supplied with $40 \mathrm{kV}$ and a current of $40 \mathrm{~mA}$. The data were collected over a range of $2-30^{\circ} 2 \theta$ with a step size of $0.026^{\circ} 2 \theta$ and nominal time per step of $100 \mathrm{~s}$, using the scanning PIXcell $1 \mathrm{~d}$ detector (hence the counting time per step). Fixed anti-scatter and divergence slits of $1 / 16^{\circ}$ and $1 / 32^{\circ}$ were used together with a beam mask of $10 \mathrm{~mm}$ and all scans were carried out in 'continuous' mode. The samples were analyzed in the main direction of extrusion.

DSC analyses were performed with a Q20 TA Instruments analyzer according to the following cycle: heating up from 25 to $250^{\circ} \mathrm{C}$ at $10^{\circ} \mathrm{C} / \mathrm{min}, 1 \mathrm{~min}$ isothermal step at $250^{\circ} \mathrm{C}$, cooling down to $25^{\circ} \mathrm{C}$ at $-10^{\circ} \mathrm{C} / \mathrm{min}, 1 \mathrm{~min}$ isothermal step at $25^{\circ} \mathrm{C}$, final heating up from 25 to $250^{\circ} \mathrm{C}$ at $10^{\circ} \mathrm{C} / \mathrm{min}$. The amount of material placed in the DSC aluminum crucibles was $7-8 \mathrm{mg}$. The stress relaxation $\left(T_{\mathrm{sr}}\right)$ and melting $\left(T_{\mathrm{m}}\right)$ temperatures, stress relaxation $\left(\Delta H_{\mathrm{sr}}\right)$, and melting $\left(\Delta H_{\mathrm{m}}\right)$ enthalpies were determined from the first heating scan. The degrees of crystallinity $\left(\chi_{c}\right)$ of PAs and composites were evaluated using the Eq. $I$ and following the suggestions of Khanna and Kuhn [31] about the presence of a "sub- $T_{\mathrm{m}}$ Stress Relaxation in Nylons".

$$
\chi_{\mathrm{c}}=\frac{\Delta H_{\mathrm{m}}-\Delta H_{\mathrm{sr}}}{\Delta H_{100} \cdot(1-x)} \cdot 100
$$

where $\Delta H_{100}$ is the melting enthalpy of the $100 \%$ crystalline polymer matrix $(244 \mathrm{~J} / \mathrm{g}$ for PA10.10, $254 \mathrm{~J} / \mathrm{g}$ for PA6.10 [32]) and $x$ is the nominal filler weight percentage.

Dynamic-mechanical thermal experiments (DMTA) were performed using a DMA Q800 (TA Instruments) using a tensile film clamp. DMTA specimens were cut from film extruded samples in MD as rectangular strips with dimensions of $30 \times 6 \mathrm{~mm}^{2}$. The experimental conditions were: temperature range from 30 to $100^{\circ} \mathrm{C}$, heating rate of $3^{\circ} \mathrm{C} / \mathrm{min}$, frequency $1 \mathrm{~Hz}$, and oscillation amplitude $0.05 \%$. Prior to DMTA tests, all specimens were conditioned at $23 \pm 1{ }^{\circ} \mathrm{C}$ and $50 \%$ relative humidity (R.H.) in a climatic chamber for minimum $48 \mathrm{~h}$.

The phase angle $(\tan \delta)$ peaks are referred as $\alpha$ relaxation peaks believed to be related to the breakage of hydrogen bonding between PA chains, corresponding to the glass transition temperature $\left(T_{\mathrm{g}}\right)$ [33].

The tensile behavior of the films was determined following the ISO-527-2 standard with a universal testing machine (Zwick Z010, Zick/Röll, Ulm, Germany) equipped with a $10 \mathrm{kN}$ load cell. The test specimens were obtained from the films using a cutting press with a die. The deformation of the narrow section was measured with a contact extensometer. The testing conditions were a constant crosshead speed of $1 \mathrm{~mm} / \mathrm{min}$ and room temperature. The stress-strain curve for each specimen was recorded. Five samples were used for each formulation and the average values and corresponding standard deviation were calculated. These tests provided the elastic modulus $(\mathrm{E})$, yield strength $\left(\sigma_{y}\right)$, tensile strength $\left(\sigma_{\max }\right)$, and elongation-atbreak $(\varepsilon)$ of the bio-based materials.

Prior to mechanical tests, all specimens were conditioned at $23 \pm 1{ }^{\circ} \mathrm{C}$ and $30 \%$ R.H. in a climatic glass box for minimum $48 \mathrm{~h}$ till weight equilibrium was reached (1.0\% weight gain from the dry condition in PA10.10 and $1.7 \%$ for PA6.10).

OP and WP were measured by using a Multiperm ExtraSolution instrument. The experimental conditions were set at $23^{\circ} \mathrm{C}$ and $50 \%$ R.H., with an initial conditioning time of $15 \mathrm{~h}$.

The film with an area equal to $50 \mathrm{~cm}^{2}$ was placed between the two halves of the permeability chamber and flushed with a nitrogen at a flow rate of approximately $70 \mathrm{~mL} / \mathrm{min}$ to completely remove traces of oxygen or water. The apparent OTR and water vapor transmission rate (WTR) under nitrogen was measured to give information on the background count due to leaks in the system. The gas flow was in half of the cell then switched to oxygen or humid nitrogen and the sample left to equilibrate. The end of the test was established when the collected data reached an OTR or WTR steady state accuracy of $0.5 \%$. OTR and WTR values were automatically given by the instrument on the basis of the atmospheric pressure depending on weather conditions. OP and WP were then calculated after measuring film thickness by a micrometer device.

\section{Evaluation of the Clay Interactions by Pukanszky's B Factor}

Following the research and validation of the model made by Százdi et al. [34], in this article, the Pukanszky's model [35] Eq. 2 was used to describe the composition dependence of the filled polymers to the tensile yield stress.

$$
\log \left(\sigma_{\text {red }}\right)=\log \frac{\sigma_{\mathrm{c}} \cdot\left(1+2.5 \cdot \varphi_{\mathrm{f}}\right)}{\sigma_{\mathrm{m}} \cdot\left(1-\varphi_{\mathrm{f}}\right)}=B \cdot \varphi_{\mathrm{f}}
$$

where $\sigma_{\mathrm{c}}$ and $\sigma_{\mathrm{m}}$ are the yield stress of the composite and the matrix, respectively, $\varphi_{f}$ the volume fraction of the filler in the composites. The value of parameter $B$ depends on all factors influencing the load-bearing capacity of the filler that is, on the strength of interaction and on the size of the contact surface [36] as reported in Eq. 3.

$$
B=\left(1+\mathrm{A}_{\mathrm{f}} \cdot \rho_{\mathrm{f}} \cdot 1\right) \cdot \log \frac{\sigma_{\mathrm{yi}}}{\sigma_{\mathrm{m}}}
$$

where $A_{\mathrm{f}}$ is the specific surface area of the filler (contact surface), $\rho_{\mathrm{f}}$ is its density, while $l$ and $\sigma_{\mathrm{y} i}$ are the thickness 

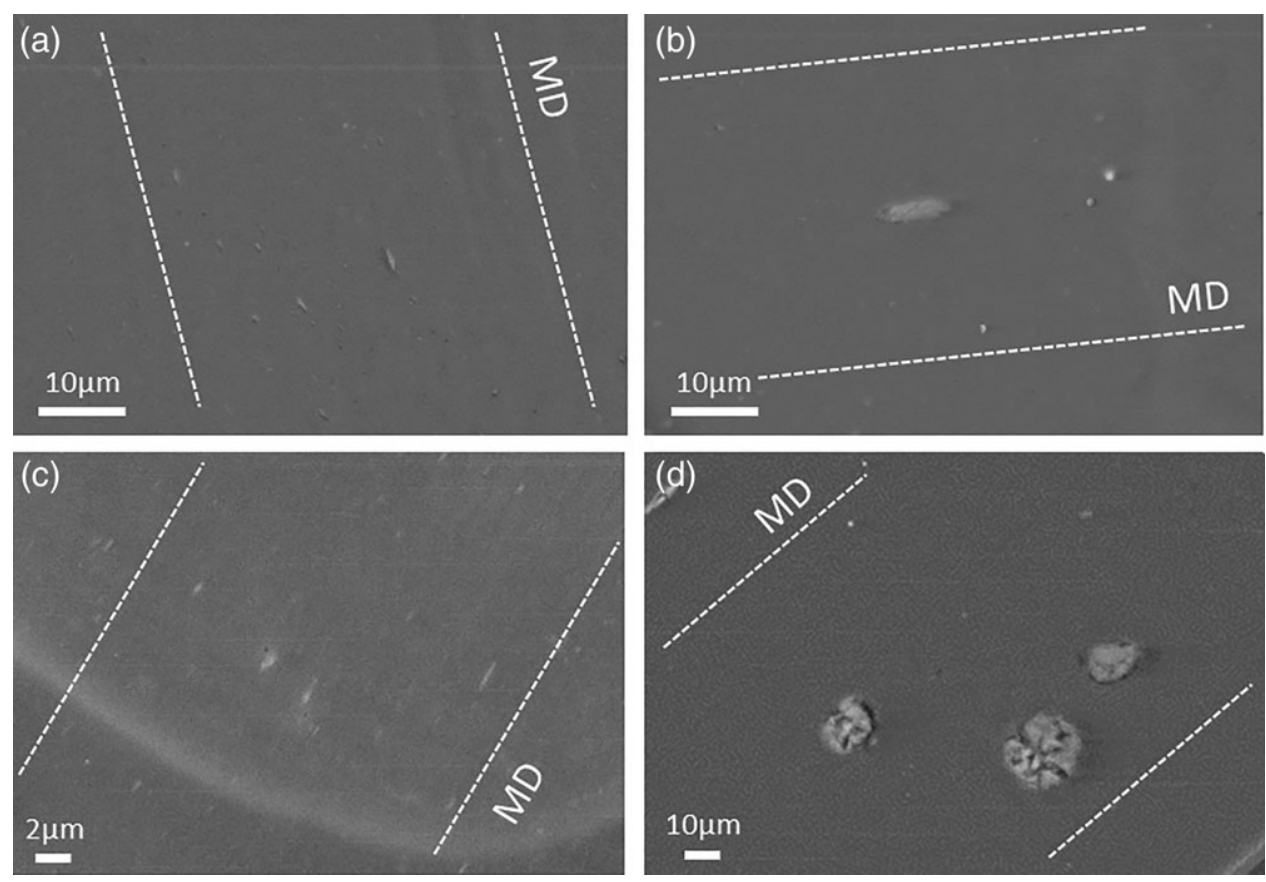

FIG. 2. SEM micrographs of: PA10.10_5C $(a, b)$ and PA6.10_5C $(c, d)$; the dotted lines follow the extrusion direction (MD).

and the yield stress of the interphase. The latter two parameters were shown to depend on the strength of matrix/filler interaction [37] while the contact surface between the matrix and the silicate increases with increasing the extent of exfoliation [34].

Thus the value of parameter $B$ should increase proportionally to the degree of exfoliation if the other parameters remain constant.

Szazdi et al. [34] have calculated a $B$ factor of 1.8 for unmodified MMT without any kind of exfoliation and a $B$ factor of 195 assuming a complete exfoliation. These two cases represent the boundaries for zero and maximum reinforcement. Considering all the other factors are the same, the $B$ value linearly depends on the specific surface area of the filler. Thus, the extent of exfoliation is calculated by applying Equation 4 .

$$
\% \text { of exfoliation }=\frac{B-1.8}{195-1.8} \cdot 100
$$

\section{RESULTS AND DISCUSSION}

\section{Composites Filler Amount}

The quantity of C30B ash from melt-blended composites was measured after thermal treatment in a muffle till $800^{\circ} \mathrm{C}$. The remaining weight percentage of minerals for PA10.10_5C and PA6.10_5C composites are $3.40 \pm 0.07$ and $3.57 \mathrm{wt} \% \pm 0.10$, respectively. The clay concentrations are easily computable because the organic surface treatment for this grade is known (30 wt\%). This makes it likely that there is between 4.86 and $5.10 \mathrm{wt} \%$ of modified clay in the composites. By this way, the correctness and accuracy of the nominal filler quantity were verified.

\section{Morphological Analysis}

The cryofracture surfaces morphology of bio-composites was investigated by SEM and reported in Fig. 2. SEM observation was used to qualitatively visualize the state of dispersion of the modified clay into the different PAs. The bright dots well visible notwithstanding the matrix type are the agglomerated layers of clay. Their biggest dimensions are approximately $500 \mathrm{~nm}$ but many particles under $100 \mathrm{~nm}$ are also present. It is clear that in both bio-PA matrices under study the clay is not very well exfoliated as in other more polar PA like PA6 or PA6.6 [18,28]. Another important evidence is that the packed layers are preferentially aligned in the extrusion machine direction (MD). Indeed, as other authors have verified, clay platelets have a high tendency to orient themselves in the flow direction during the cast film process [18]. Nevertheless, from Fig. 2b and d some agglomerates are visible. It is well known that a relatively high clay content of $5 \mathrm{wt} \%$ is difficult to completely exfoliate in thermoplastic matrices and typically forms agglomerations.

\section{Crystallinity Studies With XRD and DSC Analyses}

The X-ray analysis has been used to determine the crystal structure of each studied PAs and to evaluate any changes because of the clay addition. 
(a)

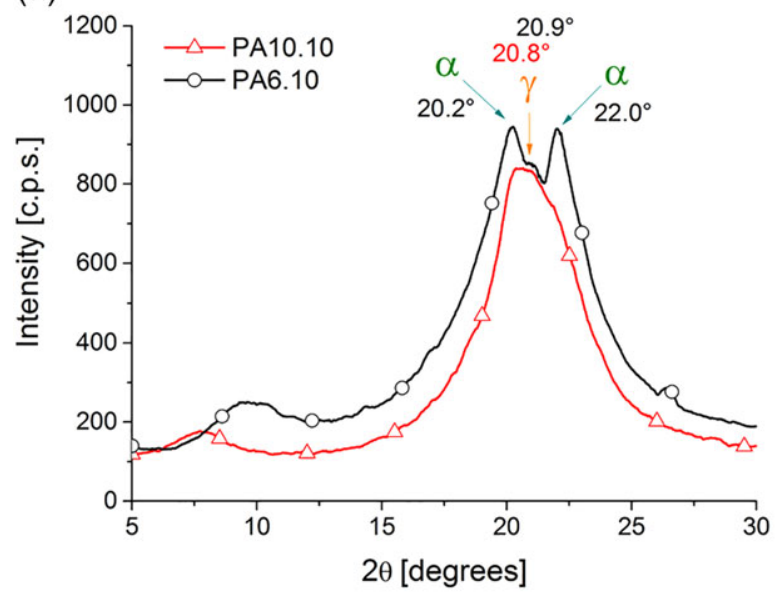

(b)

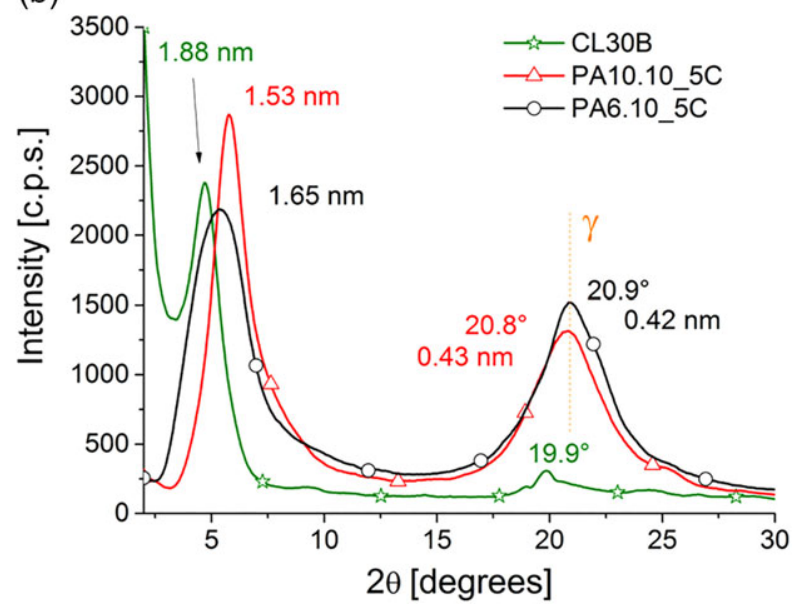

FIG. 3. XRD of: film extruded PAs (a) and composites with clay (b). [Color figure can be viewed at wileyonlinelibrary.com]

As expected, the XRD spectra of the extruded film in Fig. 3a shows that the neat PA6.10 presents the characteristic peaks of both $\gamma$ (strong equatorial single reflection at $2 \theta$ $=20.8-20.9^{\circ}$ ) and $\alpha$ (double reflections at $2 \theta=20.2^{\circ}$ and $22.0^{\circ}$ ) crystalline form, while the PA10.10 presents only the $\gamma$ form. Moreover, this latter result could be prevented considering the presence of fewer amide groups in the polymer chains and thus the less ability to form the hydrogen bond between chains.

The addition of clay $\mathrm{C} 30 \mathrm{~B}$ prevents the crystallization in the $\alpha$-form and promotes the $\gamma$-form. Indeed, the resulting composite spectra in Fig. 3b shows the presence of only one peak around $20.9^{\circ}$ for all the PAs.

A second important information from the spectra in $3 b$ is obtainable. Indeed, the peaks appearing below $10^{\circ}$ are characteristic of the exfoliation level of the clay. As expected from the SEM observation the clay peak is still present in all the composites confirming the presence of ordered layers. Deep analyzing the interlayer distances, non-treated montmorillonite exhibits a peak at around $7^{\circ}$ that corresponds to $\mathrm{d}_{001}$ spacing of $1.25 \mathrm{~nm}$ in accordance with the literature [12]. When montmorillonite is modified like C30B, the small-angle diffraction peak is shifted toward smaller angles. Thus, the spacing between the layers increases. From the reported XRD pattern, this distance was calculated and was equal to $1.88 \mathrm{~nm}$. As far as $\mathrm{C} 30 \mathrm{~B}$ was introduced in the bio-PAs, the interlayer distance is reduced to 1.65 for PA6.10 and 1.53 for PA10.10.

Generally, when an exfoliated nanocomposite is obtained, no peaks due to the 001 plane of platelets are visible. If there is an intercalation of the polymer inside the clays, the interlayer distance increases. In the case reported in this research, the reduction of such distance can be attributed to the re-arrangement of the organic modifier present in the C30B. This modification can occur according to a chemical interaction or due to the effect of shear during the extrusion process. This latter case is supposed and it is due to the longitudinal elongation stretching in the extrusion process that aligns the clay layers and also the conformation of the aliphatic chains of the organic modifier between the layers [38].

The more the peak is narrow, the more the distribution of the distance between the lamellae is similar. A sharp peak was found for PA10.10 while a broader one was reported for PA6.10. From this observation, the last matrix is considered to have more affinity with the modified clay because a population of intercalated lamellae is also present. Conversely, C30B seems to undergo a greater shear in the PA10.10 matrix reflected in a lower interlamellar distance, but not intercalation for the lower polarity of the matrix.

To complete the study on the crystallinity of the extruded film, DSC analyses have been performed. By this way, stress relaxation and melting temperatures and enthalpies registered in the heating scan were reported in Table 1 and a representative curve is reported in Fig. 4. Only the heating scan is reported as it is important to understand the crystallinity of the stretched film $\left(\chi_{c}\right)$ for the applicative field. Indeed, it has been reported that incomplete crystallization of aliphatic PAs may occur upon quenching from the melt. This crystallization is reflected in a difference in the $\chi_{\mathrm{c}}$ and in the occurrence of crystal reorganization effects during the first heating above $T_{\mathrm{g}}[19,31]$. All these rearrangements are reported as stress relaxation temperature $\left(T_{\mathrm{sr}}\right)$ and enthalpy $\left(\Delta H_{\mathrm{sr}}\right)$ in Table 1.

As far as melting temperatures were concerned, no significant differences between matrices and composites were detected. The stress relaxation temperature and enthalpy have a different behavior in the two matrices. Practically no change in PA10.10 matrix is observed when C30B is introduced while a significant increase in the $\mathrm{T}_{\mathrm{sr}}$ and a decrease in the $\Delta H_{\text {sr }}$ are visible in PA6.10 matrix. This difference can be attributed to the different crystalline structure ( $\alpha$ and $\gamma$ or only $\gamma$ form) detected in the PA6.10 matrix 
TABLE 1. DSC and DMTA data of film extruded PAs, composites and post mechanical tests.

\begin{tabular}{|c|c|c|c|c|c|c|c|c|c|}
\hline PA10.10_5C & $73 \pm 1$ & 171 & 199 & 1.4 & 53.3 & 22.4 & 198 & 67.0 & 28.9 \\
\hline PA6.10 & $85 \pm 1$ & 132 & 219 & 11.2 & 71.5 & 23.7 & 219 & 72.7 & 28.6 \\
\hline PA6.10_5C & $71 \pm 1$ & 193 & 219 & 1.1 & 46.2 & 18.2 & 220 & 77.2 & 32.0 \\
\hline
\end{tabular}

${ }^{\mathrm{a}}$ From $\tan \delta$, DMTA analysis

by the XRD analysis that reorganized the crystalline structure on heating as happened in PA6 [20].

Since PA6.10 is more polar as compared with PA10.10, the former develops a higher degree of crystallinity, namely 24 versus $21 \%$ in the heating scan.

Although the clay addition did not significantly affect the crystal fraction in the PA10.10 film, it dramatically lowered the crystallinity of PA6.10 film from 24 to $18 \%$, even to values below the neat PA10.10. It has been reported that the presence of silicate layers restricts the formation of large crystalline domains due to limited space availability and motion restrictions imposed on polymer chains [39]. Thus, a large number of silicate platelets leads to smaller crystallite structures, more defect-ridden crystalline lamella and finally a possible lower crystallinity. All these remarks are realistically valid for both PAs, but they can be found only in the PA6.10_5C sample. It could be ascribed to the film processing conditions that reduce the crystallization ability of material, but also to a better dispersion of modified clay that creates more restrictions to the crystal growth. This fact is supported by XRD analyses that showed a wider peak for this sample.

The study of the glass transition temperature $\left(T_{\mathrm{g}}\right)$ of the materials was carried out through the DMTA analysis. The presence of humidity that evaporates near the $T_{\mathrm{g}}$ temperature of the materials makes its identification complex through the DSC technique. The $T_{\mathrm{g}}$ data have been

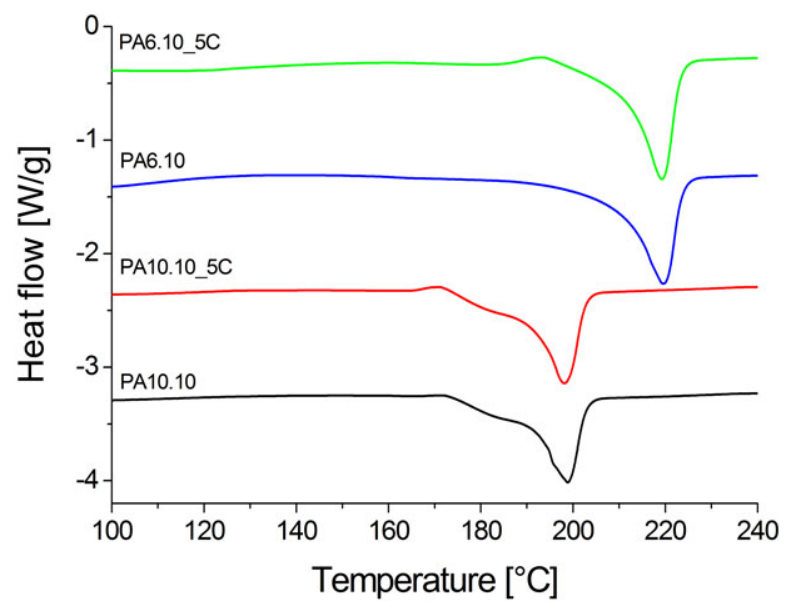

FIG. 4. DSC heating scan of film extruded PAs and composites with clay [Color figure can be viewed at wileyonlinelibrary.com] obtained from the maximum value of the $\tan \delta$ and have been shown in the Table 1 . It can be seen that the $T_{\mathrm{g}}$ value of the PA10.10_5C shifted to a slightly higher temperature compared with the neat PA10.10. This is a known phenomenon due to the interaction between the clay and the matrix which constrains the movement of the polymer chain segments [12]. Concerning the PA6.10 matrix, the phenomenon is reversed. Indeed, a decrease in $T_{\mathrm{g}}$ is found with the addition of clay. Probably, the variation in the crystallinity amount and type has a key role more than the presence of clay.

\section{Mechanical Properties}

It is well established that the structure of the crystalline and amorphous phases strongly influences the mechanical properties of the films as well as the presence of a filler $[25,26,28,39]$. Furthermore, the chain orientation, due to the film stretching during the calendering, generates anisotropic material that could be evaluated from the mechanical data. For this purpose, samples in the main extrusion direction (MD) and in the transversal direction (TD) have been cut and mechanically tested.

Tensile stress-strain properties of the neat PAs and clay composites in both directions are listed in Table 2 and a representative curve in MD is plotted in Fig. 5.

The clay addition resulted in a higher stiffness with respect to the corresponding matrices. Regarding PA10.10, tensile modulus $(\mathrm{E})$ and yield strength $\left(\sigma_{\mathrm{y}}\right)$ increased in the MD by 68 and $21 \%$, respectively. Similar results have been found by Liu et al. [12] for PA10.10 with $5 \mathrm{wt} \%$ of a modified clay that gave an increase of 44 and $22 \%$ in the tensile modulus and strength, respectively. These significant enhancements in this research can be solely attributed to the reinforcing effect of the clay as previously reported, since the crystallinity in the composite was not essentially altered with respect to the neat PA10.10. As far as PA6.10 was concerned, stiffness and yield strength in MD increased by only 14 and 5\%, respectively. The crystal fraction in this matrix decreased from 24 to $18 \%$ and changed in crystalline form with the clay addition. Consequently, the reinforcing effect of the clay was attenuated with respect to PA10.10 composites. Indeed, several studies $[8,22,24,25]$ have already pointed out how the $\alpha$ phase in PA gives a more rigid and less ductile material compared with the $\gamma$ phase. 
TABLE 2. Mechanical properties of film extruded neat PAs and composites.

\begin{tabular}{|c|c|c|c|c|c|c|c|c|}
\hline & \multicolumn{2}{|c|}{ PA10.10 } & \multicolumn{2}{|c|}{ PA10.10_5C } & \multicolumn{2}{|c|}{ PA6.10 } & \multicolumn{2}{|c|}{ PA6.10_5C } \\
\hline & MD & $\mathrm{TD}$ & MD & TD & MD & TD & MD & TD \\
\hline $\begin{array}{l}\mathrm{E}[\mathrm{MPa}] \\
\Delta\end{array}$ & $911 \pm 134$ & $1,081 \pm 45$ & $\begin{array}{l}1,533 \pm 65 \\
+68 \%\end{array}$ & $\begin{array}{l}1,525 \pm 69 \\
+41 \%\end{array}$ & $1,468 \pm 38$ & $1,331 \pm 89$ & $\begin{array}{l}1,672 \pm 213 \\
+14 \%\end{array}$ & $\begin{array}{l}1,562 \pm 120 \\
+17 \%\end{array}$ \\
\hline $\begin{array}{l}\sigma_{\mathrm{y}}[\mathrm{MPa}] \\
\Delta\end{array}$ & $30.3 \pm 1.9$ & $34.7 \pm 0.4$ & $\begin{array}{l}36.7 \pm 1.8 \\
+21 \%\end{array}$ & $\begin{array}{l}37.8 \pm 0.8 \\
+9 \%\end{array}$ & $41.0 \pm 1.6$ & $37.7 \pm 1.8$ & $\begin{array}{l}43.0 \pm 0.5 \\
+5 \%\end{array}$ & $\begin{array}{l}40.4 \pm 0.6 \\
+7 \%\end{array}$ \\
\hline $\begin{array}{l}\sigma_{\max }[\mathrm{MPa}] \\
\Delta\end{array}$ & $66.1 \pm 5.1$ & $67.9 \pm 3.5$ & $\begin{array}{l}59.3 \pm 4.6 \\
-10 \%\end{array}$ & $\begin{array}{l}54.5 \pm 3.6 \\
-20 \%\end{array}$ & $77.9 \pm 4.8$ & $67.2 \pm 11.0$ & $\begin{array}{l}59.4 \pm 5.3 \\
-24 \%\end{array}$ & $\begin{array}{l}51.7 \pm 2.5 \\
-23 \%\end{array}$ \\
\hline $\begin{array}{l}\varepsilon[\%] \\
\Delta\end{array}$ & $205 \pm 4$ & $224 \pm 17$ & $\begin{array}{l}176 \pm 11 \\
-15 \%\end{array}$ & $\begin{array}{l}175 \pm 14 \\
-22 \%\end{array}$ & $235 \pm 7$ & $214 \pm 26$ & $\begin{array}{l}179 \pm 14 \\
-24 \%\end{array}$ & $\begin{array}{l}154 \pm 12 \\
-28 \%\end{array}$ \\
\hline
\end{tabular}

$\Delta=($ value composite - value matrix $) /$ value matrix $\times 100$

Both composites are less ductile than the matrices. To be more precise, a reduction of 15 and $24 \%$ in the elongation at break $(\varepsilon)$ and $10 \%$ and $24 \%$ in the ultimate tensile strength $\left(\sigma_{\max }\right)$ was observed for PA10.10 and PA6.10, respectively. The decrease in the maximum tensile strength of both composites as compared with their matrices suggests clay agglomeration and/or poor compatibility between the PAs and clay. A relatively high clay content of $5 \mathrm{wt} \%$ is difficult to completely disperse in thermoplastic matrices and typically forms agglomerations as seen in the SEM and XRD observations. Both matrices showed significant strain hardening after the yield point and a cold drawing phase. During strain hardening the molecular chains are oriented in the load direction and the material load bearing ability is increased. Unfortunately, the addition of clay changes this ability for both PAs by contemporaneously reducing the maximum tensile strength and the strain at break. Newly, this effect is linked to the presence of agglomerated filler which acts as stress concentrator and causes the breakage prematurely.

However, it must be highlighted that the final elongations are surprisingly high with respect to other results reported in the literature. As an example, Al-Mulla [40] has found that the presence of organoclay (Cloisite 30B) strongly affected the tensile properties of the composite prepared by injection molding. Neat PA6.10 exhibited

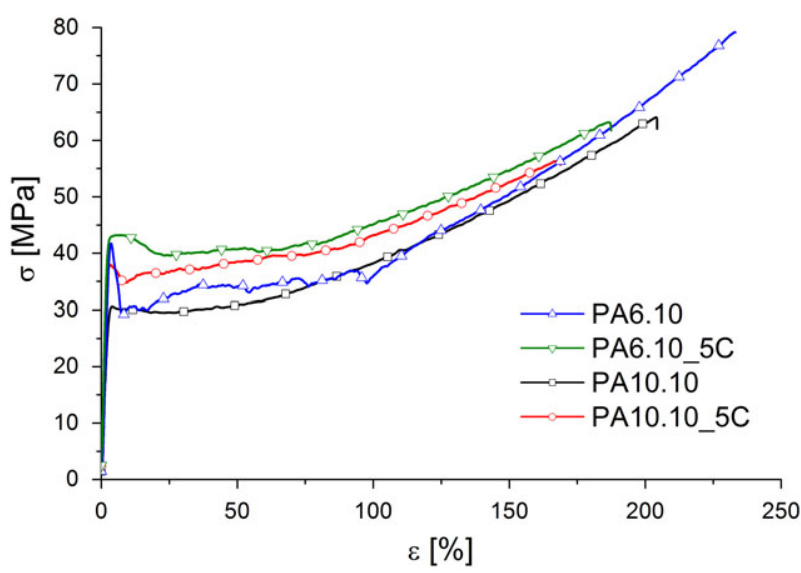

FIG. 5. Stress-strain representative curves of film extruded PAs and composites with clay [Color figure can be viewed at wileyonlinelibrary.com] cold-drawing beyond the yield stress and its strain-at-break was approximately $120 \%$. A loading of $1 \mathrm{wt} \%$ of nanoclay reduced the ultimate strain at break to $23 \%$ and 3 or $5 \mathrm{wt} \%$ to approximately $8 \%$. In the composites reported in this research, the worst elongation at break in MD still remains over $170 \%$. It seems that this unexpected effect is due to the different adopted process (film extrusion vs. injection molding) also linked to the final thickness of the tested sample. Indeed, a great reduction in the ductility of AlMulla PA6.10 composites is not repeated in the reported PA6.10_5C sample using the same modified clay. On the other hand, a similar result on film extruded samples was already reported in PLA matrix and Cloisite 30B [41]. This trend is extremely important for the possible use of the film in packaging application, where a great elongation before break is required.

Finally, an evaluation of the anisotropy is presented. PA10.10 neat matrix presents slightly better performances in the TD with respect to the MD. This unexpected result reveals that the adopted extrusion conditions never orient the film in the main direction.

This trend is extremely mitigated or not appreciable in the PA10.10_5C composite, considering the uncertain of the measurements. Nevertheless, the extrusion parameters are the same as used for the neat matrix. Thus, it seems that the clay presence is able to increase better the properties in the MD of the film sheet, probably because of its orientation that caused also the orientation of the PA chains.

The PA6.10 film presents a more common orientation in the MD attested by the slightly higher mechanical parameters in the MD with respect to the TD. Exactly the same trend is found in the PA6.10_5C sample.

\section{Evaluation of the Clay Interactions by Pukanszky's}

$\boldsymbol{B}$ Factor. To better understand the quality of the interfacial bonding, Pukanszky's model was applied to the different composites. As a result of this model, the plot of reduced stress at yield $\left(\log \sigma_{\text {red }}\right)$ as a function of volumetric fractions $\left(\varphi_{f}\right)$ in Fig. 6 is reported. The slope of the interpolated straight line that passes through the origin represents the " $B$ " parameter. As explained, $B$ is the term that corresponds to the load carrying capability of the filler and depends on the filler-matrix interactions [34]. 


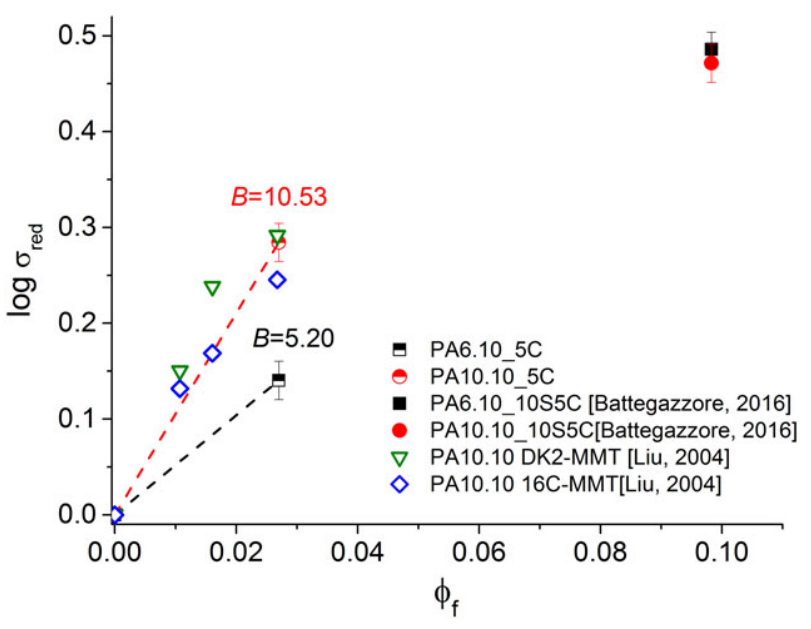

FIG. 6. Reduced stress data $\left(\log \sigma_{\text {red }}\right)$ of PA6.10- and PA10.10-based composites with fitting lines according to Pukanszky's model as a function of volumetric fraction $\left(\varphi_{\mathrm{f}}\right)$. Literature data from ref. [10,12]. [Color figure can be viewed at wileyonlinelibrary.com]

Comparing the two PA matrices, the PA10.10 exhibits the highest $\log \sigma_{\text {red }}$ value and, consequently, the highest $B$ factor (10.53). This fact seems to contradict the previous results where a lower clay exfoliation and a worse chemical compatibility are achieved with this matrix. The explanation for this result is that in the case of PA6.10, the $B$ factor (5.20) is due to two aspects: the change in the crystallinity (amount and type) between the neat sample and the composite and the dispersion degree of the clay. Specifically, the first aspect tends to decrease the $B$ factor, but it is not possible to discriminate between the two single effects.

Liu et al. [12] investigated two types of PA10.10/MMT nanocomposites by melt intercalation using a corotating twin-screw extruder. DK2-MMT is a kind of organoclay modified with methyl tallow bis(2-hydroxyethyl) ammonium cations similar to that used in this study. The data from Liu's study were processed to derive the $B$ factor. These calculations have been limited up to $5 \mathrm{wt} \%$ of filler where a linearity is verified (data reported in Fig. 6). The corresponding $B$ factor was 12.16 . The same authors investigated another clay with a different organic modifier and found a $B$ factor of 9.81 (data reported in Fig. 6). This study is therefore intermediate to the two values obtained by Liu. The simultaneous presence of Cloisite $30 \mathrm{~B}$ and silica gave instead a value of $B$ between 4.79 and 4.94 as found in a previous study with the same matrices [10] (data reported in Fig. 6).

Other studies all on PA6 have found $B$ values of 3.8 by Liu et al. [42], $B=4.2$ by Rácz et al. [43], $B=4.4-5.0$ by Shishan et al. [44], and $B=5.2-5.5$ by Fornes et al. [45]. These results are similar to those obtained in this study with PA6.10 $(B=5.20)$. On the other hand, researches with higher $B$ factor are also reported with PA6: $B=7.7-13$ by Fornes et al. $[45,46]$ with a value of 9.5 by using C30B and $B=22.9$ by Shelly et al. [47], the only reported research that used a sheet extruding machine with PA6 and clay.

Szazdi et al. [34] have estimated the extent of exfoliation by using the $B$ factor as reported in the "Evaluation of the Clay Interactions by Pukanszky's $B$ Factor" Section. The best result they reported in PA is $11.7 \%$ of exfoliation in PA6 matrix with Shelly et al.'s data [47].

Reproducing the same calculation for the data in this study on PA10.10, $4.5 \%$ of exfoliation degree is reached.

No elaborations have been discussed for PA6.10 since changing the matrix properties due to nucleation and crystallinity modification considerably changes the $B$ factor and the interfacial interactions. This makes the assumptions used for the calculation no longer valid.

Characterization Post Mechanical Tests. To deeply understand their tensile failure behavior, fractographs of neat PAs and composites after mechanical tests were investigated by using SEM. Figure 7 shows the tensile fractured surfaces of neat PAs and the $5 \mathrm{wt} \%$ clay filled ones in MD.

It is simple to observe the great differences in the fracture morphologies of neat and filled polymers. The two PAs have surfaces quite smooth with the presence of some plastic deformation visible as filaments, especially in PA6.10 sample (Fig. 7a and b). No obvious voids in the fracture surfaces were found. On the other hand, an extended content of voids was observed in the presence of clay for both matrices. These voids are also visually evident in the samples by the stress whitening effect (Fig. 7c and d).

The composite images suggest that the deformation process results from a clay/matrix debonding in the form of voiding (cavitation). For further loading, these voids grew with extensive fibrillation (shear yielding) which gives rise to the distortion and coalescence of the holes with ridge formation. Similar observations have been reported in the literature $[48,49]$.

The stress concentration introduced by the clay presence during the tensile tests may align the polymeric chains and consequently induce the polymer to crystallize. In order to investigate this possible behavior, DSC analyses on the deformed parts after mechanical tests were performed and data are reported in the last columns in Table 1. Comparing the data with the corresponding undeformed materials, no stress relaxation or crystal rearrangement peaks in the deformed materials are present and no difference in the melting temperature is registered.

The stress-induced crystallization of the stretched polymer chains has occurred as demonstrated by the increase of the crystallinity percentage in all samples. The neat PA10.10 shows a crystallinity increase from 21 to $30 \%$ (+9\%) and even the composite follows the same trend $(+7 \%)$. A different behavior is registered for the neat PA6.10, where the crystallinity is slightly increased in the neat matrix $(+5 \%)$ while it is heavily increased from 18 to $32 \%(+14 \%)$ in the composite.

PA6.10 probably also undergoes a variation in the crystalline phase during stretching [22]. The film has both $\alpha$ 


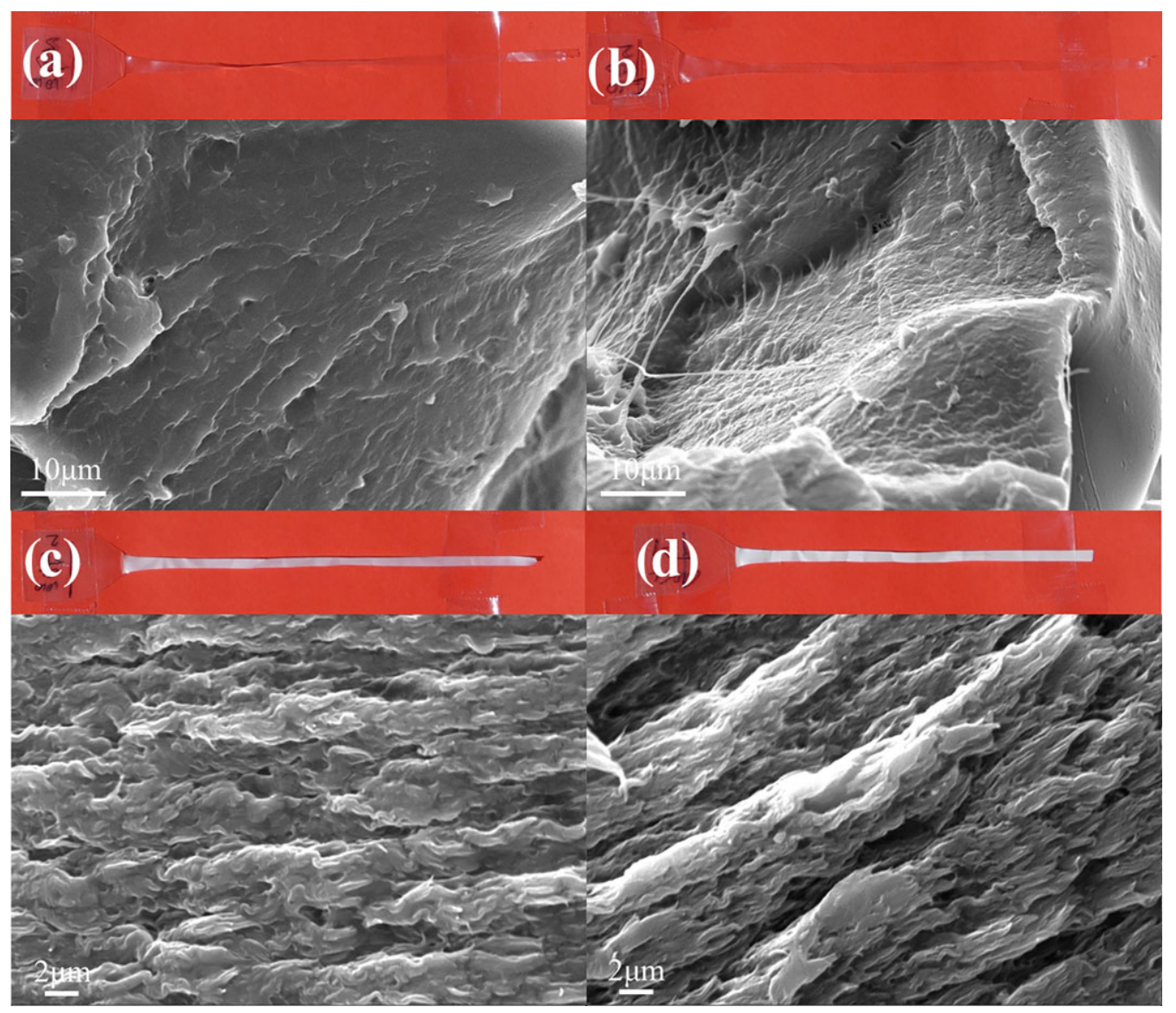

FIG. 7. SEM micrographs of the fracture surface and visual aspect of PA10.10 (a), PA6.10 (b), PA10.10_5C (c), and PA6.10_5C (d). [Color figure can be viewed at wileyonlinelibrary.com]

and $\gamma$ crystalline phases, but the $\alpha$ phase has been reported as more stable [8]. Probably a transformation $\gamma$ to $\alpha$ takes place during the test. Indeed, the tension curve in Fig. 5 is slightly different from the others: after reaching the yield peak, the supported load decreases significantly then rises until rupture. This feature is imputed in the literature to the metastable $\gamma$ or $\beta$ phase [24].

\section{Permeability}

Another important aspect of making materials suitable to the packaging industry is the possibility to protect or limit the contact between foods and oxygen, gases, water, or to prevent the aroma dispersion. To this aim, the barrier properties of the extruded films are evaluated and reported in the Table 3 as well as the film thickness.
The OP was found dependent on diffusivity thus to the path that the oxygen molecule must do to cross the film. The tortuosity of this path is at the origin of the improved barrier properties. The first cause of path increase is the crystallinity. Indeed the crystals are less permeable to the passage of oxygen and thus increase the barrier properties. This fact is at the base of the different OP of the two PAs under study. The measured OP was $7.6 \pm 0.5$ and $4.5 \pm$ $0.3 \mathrm{~cm}^{3} \times \mathrm{mm} / \mathrm{m}^{2} \times$ day $\times$ atm with a crystallinity of 21 and $24 \%$ for PA 10.10 and PA 6.10, respectively. The second improvement in the barrier properties was done by the presence of clay that further increases the tortuous path. Thus, the permeation properties are related to the clay content and dispersion. The clay addition decreases, in both matrices, the OP, achieving the best reduction $(60 \%)$ in the PA6.10_5C. This value of $1.8 \mathrm{~cm}^{3} \times \mathrm{mm} / \mathrm{m}^{2} \times$ day $\times$ atm

TABLE 3. Thickness, OP and WP of film extruded neat PAs and composites

\begin{tabular}{lccr}
\hline Permeability at 50\% R.H. & Thickness [mm] & OP $\left[\mathrm{cm}^{3} \times \mathrm{mm} / \mathrm{m}^{2} \times\right.$ day $\times$ atm $]$ & WP $\left[\mathrm{g} \times \mathrm{mm} / \mathrm{m}^{2} \times\right.$ day $]$ \\
\hline PA 10.10 & $0.16 \pm 0.01$ & $7.6 \pm 0.5$ & $0.01 \pm 0.01$ \\
PA 10.10_5C & $0.14 \pm 0.01$ & $3.7 \pm 0.2$ & $0.13 \pm 0.02$ \\
PA 6.10 & $0.15 \pm 0.01$ & $4.5 \pm 0.3$ & $0.28 \pm 0.02$ \\
PA 6.10_5C & $0.12 \pm 0.01$ & $1.8 \pm 0.2$ & $0.10 \pm 0.02$ \\
\hline
\end{tabular}


is comparable with a commercial PA6 film that generally has an OP of $1-2 \mathrm{~cm}^{3} \times \mathrm{mm} / \mathrm{m}^{2} \times$ day $\times$ atm [30].

Sabart et al. have reported that the use of a higher chillroll temperature led to a slightly lower degree of crystallinity but a higher fraction of $\gamma$ phase in the total crystalline phase of the PA6 and resulted in improved barrier properties [50]. From the results obtained in this research, it is difficult to definitely say whether this trend also occurs in these two bio-PAs. Surely, the variation in crystallinity from $\alpha$ to $\gamma$, despite the decrease in the total amount of crystallinity in PA6.10, seems to increase the barrier effect.

As far as water permeability was concerned, the trend is reverse with respect to OP. The best property is found with PA10.10 where the hydrophobic aliphatic chain is longer, reaching a value near to the sensibility of the instrument $0.01 \mathrm{~g} \times \mathrm{mm} / \mathrm{m}^{2} \times$ day.

In this case, the diffusion is not the key factor for the WP and thus crystallinity has a minor role. In addition, the clay platelets never increase the water path through the film thickness, but, contrarily, could attract them to their polar surfaces. This accumulation of molecules can act as a preferred path to pass through the film and thereby increase the WP. It is what happens in the case of PA10.10. On the other hand, the clay action is effective in reducing the PA6.10 WP because the polar preferential path on the clay particles is slower than through the neat matrix.

The two formulations with clay present a comparable $\mathrm{WP}$, confirming the fact that the water permeability is dominated by the preferential path offered by the clay and not by the matrix.

\section{CONCLUSIONS}

In this study, a fully renewable PA10.10 and a partially renewable PA6.10 were successfully melt blended with an organic modified clay and film extruded in a laboratory sheet casting machine.

A detailed study on the crystallinity has been made: PA6.10 changes the crystalline structure during the film stretching with the clay from $\alpha$ to $\gamma$ phase and the crystallinity is reduced from 24 to $18 \%$ while PA10.10 remains always in $\gamma$ form with a crystallinity around $21 \%$.

The morphological analysis reveals the orientation of the clay platelet in the extrusion direction as well as some micro aggregations which is predictable from the XRD observations.

The data collected from the tensile analyses showed that modified clay induced significant improvement in the elastic modulus (+68\% in PA10.10 and $+14 \%$ in PA6.10), as well as a slight increase in the yield strength $(+21$ and + $5 \%$, respectively), with a surprisingly low decrease in the deformation at break ( -15 and $-24 \%$, respectively) in the MD. The individual nanoparticles act as stress concentration points and relatively induce large local deformation which promoted cavitation. This fact generated whitening in the composites after loading. Moreover, a strain-induced crystallization process was revealed by the crystallinity study on samples after tensile tests. These analyses show increases of crystallinity until $29-30 \%$ in PA10.10 and $29-32 \%$ in PA6.10 for neat matrix and clay composite, respectively.

The Pukanszky's model was exploited to evaluate the interactions between the clay and the two matrices finding a better stress transfer with PA10.10. The percentage of clay exfoliation was also calculated in this system that accounts for $4.5 \%$.

Finally, the barrier properties to oxygen and water for both PAs have been measured. OP is lower in the higher crystalline PA6.10 while water permeability works reversely for the longer aliphatic chain length in the PA10.10 structure. The barrier effect was increased $(>50 \%)$ by the presence of clay in both matrices and an OP value comparable to neat PA6 of $1.8 \pm 0.2 \mathrm{~cm}^{3} \times \mathrm{mm} / \mathrm{m}^{2} \times$ day $\times$ atm with PA6.10_5C was achieved.

\section{ACKNOWLEDGMENTS}

The Authors would like to thank Mr Simone Infantino and Dott. Matteo Lavaselli for the compounding and film extrusion trials. M. Ll Maspoch acknowledges the financial support from the Spanish Ministry of Economy and Competitiveness through the project MAT2016- 80045-R (AEI/FEDER, UE).

\section{REFERENCES}

1. A. K. Mohanty, M. Misra, G. Hinrichsen, Macromolecular Materials and Engineering 2000, 276, 1.

2. A. Mohanty, M. Misra, L. Drzal, Journal of Polymers and the Environment 2002, 10, 19.

3. European Bioplastics Association, https://www.europeanbioplastics.org/, Bioplastics Facts and Figures, 2017.

4. D. A. Ruehle, C. Perbix, M. Castañeda, J. R. Dorgan, V. Mittal, P. Halley, D. Martin, Polymer 2013, 54, 6961.

5. M. Feldmann, A. K. Bledzki, Composites Science and Technology 2014, 100, 113.

6. M. Feldmann, H.-P. Heim, J.-C. Zarges, Composites Part A: Applied Science and Manufacfturing 2016, 83, 113.

7. J. Pagacz, K. N. Raftopoulos, A. Leszczyńska, K. Pielichowski, Journal of Thermal Analysis and Calorimetry 2016, 123, 1225.

8. M. Fereydoon, S. H. Tabatabaei, A. Ajji, Polymer Engineering \& Science 2015, 55, 1113.

9. D. Battegazzore, J. Alongi, G. Fontaine, A. Frache, S. Bourbigot, G. Malucelli, RSC Advances 2015, 5, 39424.

10. D. Battegazzore, O. Salvetti, A. Frache, N. Peduto, A. De Sio, F. Marino, Composites Part a-Applied Science and Manufacturing 2016, 81, 193.

11. M. Q. Yan, H. J. Yang, Polymer Composites 2012, 33, 1770.

12. Z. J. Liu, P. L. Zhou, D. Y. Yan, Journal of Applied Polymer Science 2004, 91, 1834.

13. F. Xiuwei, L. Xiaohong, Y. Laigui, Z. Zhijun, Journal of Applied Polymer Science 2010, 115, 3339. 
14. J. Breil, Biaxially Oriented Films for Packaging Applications, Plastic Films in Food Packaging. In Multilayer flexible packaging, Wagner Jr, John R., Eds., William Andrew Publishing, Oxford, (2013). http://dx.doi.org/10.1016/B978-1-4557-3112-1. 00004-1

15. F. Sadeghi, A. Ajji, International Polymer Processing 2012, 27, 565

16. B. Yalcin, Z. Ergungor, Y. Konishi, M. Cakmak, C. Batur, Polymer 2008, 49, 1635.

17. M. Bureau, J. Denault, K. Cole, G. Enright, Polymer Engineering \& Science 2002, 42, 1897.

18. E. Picard, A. Vermogen, J.-F. Gérard, E. Espuche, Journal of Membrane Science 2007, 292, 133.

19. C. Millot, L.-A. Fillot, O. Lame, P. Sotta, R. Seguela, Journal of Thermal Analysis and Calorimetry 2015, 122, 307.

20. I. Kolesov, D. Mileva, R. Androsch, C. Schick, Polymer 2011, 52, 5156.

21. N. S. Murthy, Journal of Polymer Science Part B: Polymer Physics 2006, 44, 1763.

22. V. Miri, O. Persyn, J. M. Lefebvre, R. Seguela, A. Stroeks, Polymer 2007, 48, 5080.

23. L. Penel-Pierron, C. Depecker, R. Seguela, J. M. Lefebvre, Journal of Polymer Science Part B: Polymer Physics 2001, 39, 484.

24. R. Seguela, Polymer Reviews 2005, 45, 263.

25. M. Fereydoon, Development of High Barrier Nylon Based Multilayer Films, École Polytechnique de Montréal, 2014.

26. S. Mohanty, S. K. Nayak, Polymer-Plastics Technology and Engineering 2007, 46, 367. DOI: 10.1080/03602550601156029

27. J.-T. Yeh, C.-J. Chang, F.-C. Tsai, K.-N. Chen, K.-S. Huang, Applied Clay Science 2009, 45, 1.

28. S. K. Swain, A. I. Isayev, Journal of applied polymer science 2009, 114, 2378.

29. M. Fasihi, M. R. Abolghasemi, Journal of Applied Polymer Science 2012, 125, E2.

30. J. Atkinson, in, Pergamon, 1993.

31. Y. Khanna, W. Kuhn, Journal of Polymer Science Part B: Polymer Physics 1997, 35, 2219.
32. A. Ciaperoni, A. Mula, Chimica e tecnologia delle poliammidi, Pacini Editore, Pisa, Italy 2001.

33. M. Yuan, L.-S. Turng, Polymer 2005, 46, 7273.

34. L. Százdi, A. Pozsgay, B. Pukánszky, European Polymer Journal 2007, 43, 345.

35. B. Pukanszky, Composites 1990, 21, 255.

36. A. Lazzeri, V. T. Phuong, Composites Science and Technology 2014, 93, 106.

37. G. Vörös, E. Fekete, B. Pukánszky, The Journal of Adhesion 1997, 64, 229.

38. M. Morvan, D. Espinat, J. Lambard, T. Zemb, Colloids and Surfaces A: Physicochemical and Engineering Aspects 1994, 82, 193.

39. J. Tung, R. Gupta, G. Simon, G. Edward, S. Bhattacharya, Polymer 2005, 46, 10405.

40. A. Al-Mulla, International Journal of Polymer Analysis and Characterization 2009, 14, 540.

41. E. A. Franco-Urquiza, J. Cailloux, O. Santana, Advances in Polymer Technology 2015, 34, 21470.

42. T. X. Liu, Z. H. Liu, K. X. Ma, L. Shen, K. Y. Zeng, C. B. He, Composites Science and Technology 2003, 63, 331.

43. L. Racz, B. Pukánszky, A. Pozsgay and B. Pukánszky, From Colloids to Nanotechnology, Springer, Berlin, Heidelberg (2004).

44. W. Shishan, J. Dingjun, O. Xiaodong, W. Fen, S. Jian, Polymer Engineering \& Science 2004, 44, 2070.

45. T. Fornes, P. Yoon, D. Hunter, H. Keskkula, D. Paul, Polymer 2002, 43, 5915.

46. T.D. Fornes, P.J. Yoon, H. Keskkula, D.R. Paul, Polymer 2001, 42, 09929.

47. J. Shelley, P. Mather, K. DeVries, Polymer 2001, 42, 5849.

48. S. C. Tjong, Materials Science and Engineering: R: Reports 2006, 53, 73.

49. M. L. Maspoch, O. O. Santana, J. Cailloux, E. Franco-Urquiza, C. Rodriguez, J. Belzunce, A. B. Martinez, Express Polymer Letters 2015, 9, 185.

50. M. Sabard, F. Gouanvé, E. Espuche, R. Fulchiron, L.-A. Fillot, L. Trouillet-Fonti, Journal of Membrane Science 2014, 456, 11. 